\title{
Large homozygous RAB3GAP1 gene microdeletion causes Warburg Micro Syndrome 1
}

\author{
Sylvie Picker-Minh ${ }^{1,2,3}$, Andreas Busche ${ }^{4}$, Britta Hartmann ${ }^{4}$, Birgit Spors ${ }^{5}$, Eva Klopocki ${ }^{6,7}$, Christoph Hübner ${ }^{1}$, \\ Denise Horn ${ }^{6}$ and Angela M Kaind1 ${ }^{1,2,3^{*}}$
}

\begin{abstract}
Warburg micro syndrome (WARBM) is a genetic heterogeneous disease characterized by microcephaly, intellectual disability, brain, ocular, and endocrine anomalies. WARBM1-4 can be caused by biallelic mutations of the RAB3GAP1 (RAB3 GTPase-activating protein 1), RAB3GAP2, RAB18 (RAS-associated protein RAB18), or TBC1D20 (TBC1 domain protein, member 20) gene, respectively. Here, we delineate the so far largest intragenic homozygous RAB3GAP1 microdeletion. Despite the size of the RAB3GAP1 gene deletion, the patient phenotype is mainly consistent with that of other WARBM1 patients, supporting strongly the theory that WARBM1 is caused by a loss of RAB3GAP1 function. We further highlight osteopenia as a feature of WARBM1.
\end{abstract}

Keywords: RAB3GAP1, WARBM, Warburg micro syndrome, Microcephaly, Intellectual disability, Congenital cataract, Array CGH

\section{Letter to the editor}

Warburg micro syndrome (WARBM) is a rare autosomal recessive disorder characterized by neurodevelopmental abnormalities such as congenital or postnatal microcephaly, severe intellectual disability, pachy- or polymicrogyria, and hypoplasia/agenesis of the corpus callosum as well as ocular manifestations including congenital cataract, microcornea, microphthalmia, and optic atrophy [1-3]. Further features of WARBM comprise hypothalamic hypogonadism, epilepsy, limb spasticity, and joint contractures. WARBM1 (MIM\#600118) is caused by biallelic mutations of the RAB3 GTPase-activating protein 1 gene RAB3GAP1 (2q31; MIM*602536), WARBM2 (MIM\#614225) by mutations of the RAB3 GTPase-activating protein 2 gene RAB3GAP2 (1q41; MIM*609275), WARBM3 (MIM\#614222) by mutations of the RAS-associated protein RAB18 gene RAB18 (10p12.1; MIM*602207), and WARBM4 (MIM\#615663) by mutations in the TBC1 domain protein, member 20, gene TBC1D20 (MIM*611663). Most mutations were predicted to result in nonsense-mediated mRNA decay and/or loss-of-

\footnotetext{
* Correspondence: angela.kaindl@charite.de

'Department of Pediatric Neurology, Charité - Universitätsmedizin Berlin,

Campus Virchow-Klinikum, Augustenburger Platz 1, 13353 Berlin, Germany

${ }^{2}$ SPZ Pediatric Neurology, Charité - Universitätsmedizin Berlin, Campus

Virchow-Klinikum, Augustenburger Platz 1, 13353 Berlin, Germany

Full list of author information is available at the end of the article
}

protein-function [1,2,4-7], putatively explaining the lack of a genotype-phenotype correlation. We here report the largest RAB3GAP1 gene microdeletion to date in patients with WARBM1 and compare their phenotype with that of other WARBM1 patients. The two index patients were born at term without complications as the first and second child of healthy, consanguineous parents of KurdishArmenian descent (Figure 1). Pregnancies were uneventful, and anthropometric data in the first months of life were reported to be normal by the parents. Both patients were diagnosed with bilateral cataracts in the first months of life, and cataract surgery was performed in patient IV.2. The parents noted progressive hypotonia with loss of head control and finally developmental delay when their child did not attempt to roll within the first year of life. At first presentation at 6 (IV.1) and 5 (IV.2) years-of-age, the patients were not able to roll over, sit, stand, or speak, exhibited a short stature, dystrophy, and microcephaly (IV:1: height $90 \mathrm{~cm}, 16 \mathrm{~cm}<3$. centile, $-5.2 \mathrm{SD}$; weight $11 \mathrm{~kg}, 4 \mathrm{~kg}<3$. centile, -3.4 SD; head circumference $47 \mathrm{~cm}$, $1.5 \mathrm{~cm}<3$. centile, -2.6 SD; IV.2: height $95 \mathrm{~cm}, 6 \mathrm{~cm}<3$. centile, $-3.3 \mathrm{SD}$; weight $10,3 \mathrm{~kg}, 5 \mathrm{~kg}<3$. centile, $-3.7 \mathrm{SD}$; head circumference $45 \mathrm{~cm}, 4 \mathrm{~cm}<3$. centile, $-3.8 \mathrm{SD}$ ), and had bilateral cataracts (unilateral iatrogenic aphakia in IV.2), microcornea, and microphthalmia. Bilateral cryptorchidism was present in IV.2. In both patients, poor head 


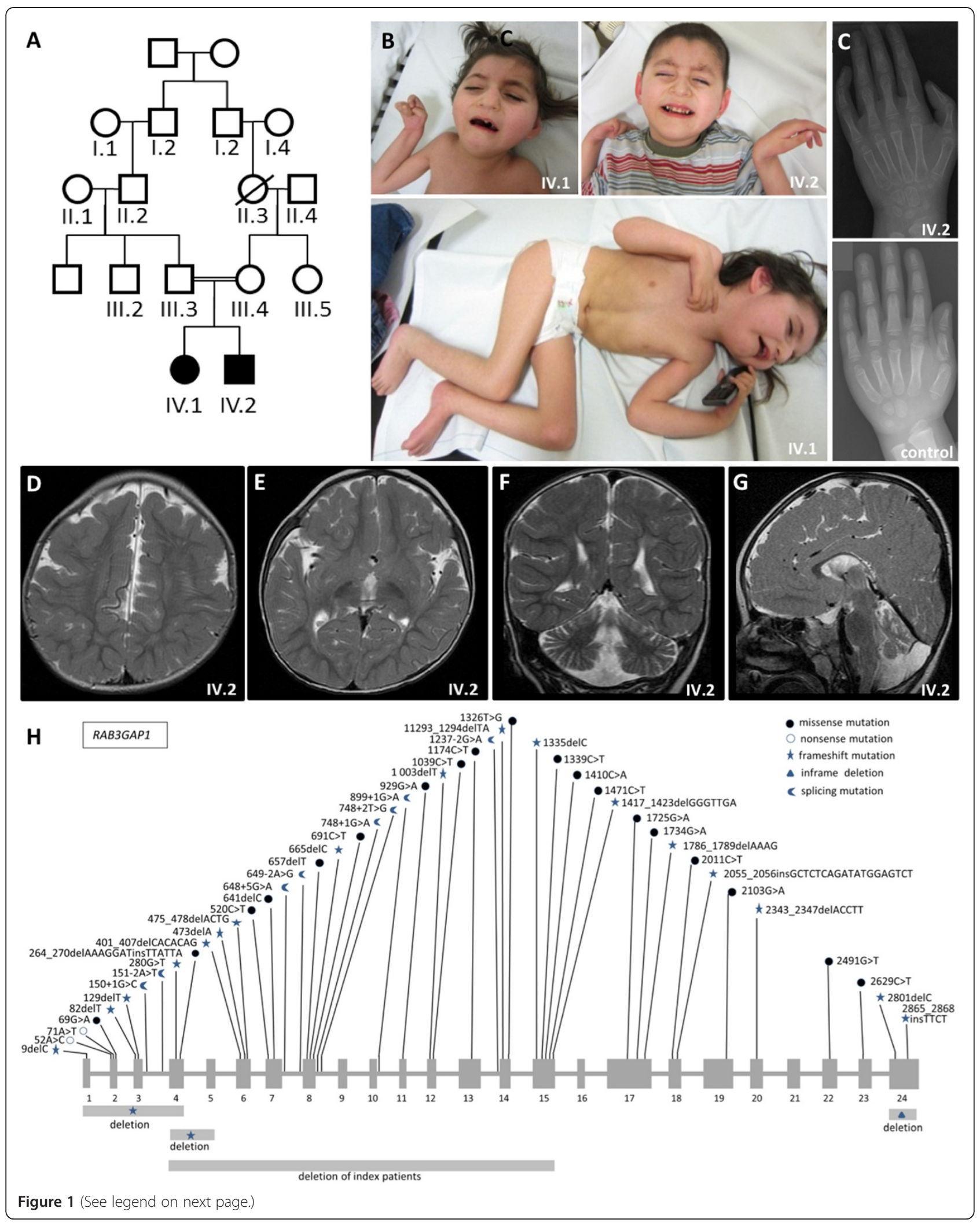


(See figure on previous page.)

Figure 1 Phenotype of the index patients with WARBM1. (A) Pedigree. (B) Pictures of the index patients illustrating severe dystrophy, microcephaly, and distal contractures. Facial features include a prominent nasal root, relatively short nose, large ears, and a mild facial hypertrichosis. (C) Appropriate skeletal age but severe osteopenia on conventional X-rays of left hand of patient IV.2 when compared to an age- and sex-matched control. (D-G) Cranial MRI of patient IV.2 revealed parietal pachygyria (D, axial T2), widened sylvian fissure (E, axial T2), cerebellar atrophy ( $\mathbf{F}$, coronal T2), and corpus callosum dysmorphism with agenesis of the splenium corpi (G, sagittal T2). (H) Scheme depicts all previously reported mutations in the RAB3GAP1 gene in patients with WARBM1 and the novel deletion in our index patients.

Table 1 Comparison of phenotypic features of the index patients with those described in other patients with Warburg micro syndrome 1-3 and Martsolf syndrome

\begin{tabular}{|c|c|c|c|c|c|c|c|}
\hline Characteristics and symptoms & HPO ID & Patient & Patient & WARBM1 & WARBM2 & WARBM3 & MS \\
\hline Pedigree ID & & $\| .1$ & 11.2 & & & & \\
\hline Gender & & Female & Male & & & & \\
\hline Age at last assessment (years) & & 5.9 & 4.5 & & & & \\
\hline \multicolumn{8}{|l|}{ Growth } \\
\hline Short stature & 0004322 & + & + & + & + & + & + \\
\hline Postnatal failure to thrive & 0001508 & + & + & + & + & + & + \\
\hline Growth hormone deficiency & 0000824 & + & + & NR & NR & NR & + \\
\hline \multicolumn{8}{|l|}{ Head and neck } \\
\hline Postnatal microcephaly & 0000252 & + & + & + & + & + & $(+)$ \\
\hline Micrognathia & 0000347 & + & - & + & - & - & + \\
\hline Large ears & 0000400 & - & + & + & + & - & - \\
\hline Microphthalmia & 0000568 & + & + & + & + & + & + \\
\hline Microcornea & 0000482 & + & + & + & + & + & + \\
\hline Congenital cataract & 0000519 & + & + & + & + & + & + \\
\hline Ptosis & 0000508 & - & - & $(+)$ & - & - & - \\
\hline Nystagmus & 0000639 & - & - & $(+)$ & - & - & - \\
\hline Epicanthal folds & 0000286 & - & - & - & - & - & + \\
\hline \multicolumn{8}{|l|}{ Genitourinary } \\
\hline Cryptorchism & 0086889 & NA & + & + & + & + & + \\
\hline Hypogenitalism & 0003241 & - & + & + & + & + & + \\
\hline \multicolumn{8}{|l|}{ Skeletal } \\
\hline Osteoporosis & 0000939 & ++ & ++ & NR & NR & NR & NR \\
\hline Kyphoscoliosis & 0002751 & + & + & + & NR & + & + \\
\hline Joint hypermobility & 0001382 & - & - & $(+)$ & - & - & - \\
\hline Joint contractures & 0002803 & + & + & + & + & + & - \\
\hline Foot deformities & 0001760 & - & - & + & + & - & + \\
\hline \multicolumn{8}{|l|}{ Hair } \\
\hline Facial hypertrichosis & 0002219 & + & + & + & - & - & - \\
\hline \multicolumn{8}{|l|}{ Neurologic } \\
\hline Intellectual deficit & 0001249 & ++ & ++ & ++ & ++ & ++ & + \\
\hline Optic atrophy & 0000658 & + & + & + & + & + & - \\
\hline Hyperreflexia & 0007034 & + & + & + & + & + & + \\
\hline Muscular hypotonia & 0001290 & + & + & + & + & + & + \\
\hline Spastic diplegia & 0001264 & + & + & + & + & + & $(+)$ \\
\hline
\end{tabular}


Table 1 Comparison of phenotypic features of the index patients with those described in other patients with Warburg micro syndrome 1-3 and Martsolf syndrome (Continued)

\begin{tabular}{|c|c|c|c|c|c|c|c|}
\hline Seizures & 0001250 & - & - & + & - & + & - \\
\hline Inability to walk & 0002540 & + & + & + & + & + & $(+)$ \\
\hline Absent speech & 0001344 & + & + & + & $(+)$ & + & $(+)$ \\
\hline \multicolumn{8}{|l|}{ Cranial MRI } \\
\hline Abnormal corpus callosum & 0001273 & + & + & + & + & + & $(+)$ \\
\hline Cerebral atrophy & 0002059 & - & - & + & $(+)$ & + & $(+)$ \\
\hline Cerebral malformations & 0007319 & - & - & + & - & - & - \\
\hline Polymicrogyria & 0002126 & - & - & + & $(+)$ & + & $(+)$ \\
\hline Pachygyria & 0001302 & + & + & + & - & - & - \\
\hline Enlarged sylvian fissures & 0100952 & + & + & + & - & + & $(+)$ \\
\hline Cerebellar hypoplasia & 0001321 & + & + & + & $(+)$ & + & - \\
\hline Dysmyelination & 0007266 & - & - & + & $(+)$ & + & - \\
\hline \multicolumn{8}{|l|}{ Cardiovascular } \\
\hline Cardiomyopathy & 0001638 & - & - & NR & $N R$ & NR & + \\
\hline Cardiac failure & 0001635 & - & - & NR & NR & NR & + \\
\hline \multicolumn{8}{|l|}{ Respiratory } \\
\hline Recurrent infections & 0002205 & - & - & NR & NR & NR & + \\
\hline
\end{tabular}

micro syndrome 1-3; MS, Martsolf syndrome.

control, sparse voluntary movements, axial hypotonia, thoracolumbar scoliosis, lower-limb-spasticity and contractures, and unilateral hip dislocation were apparent. Cranial MRI revealed bilateral parietal pachygyria, dysgenesis of the corpus callosum with agenesis of the splenium, prominent fissura sylvii, mild cerebellar atrophy, and hypotrophic optic chiasma in both patients (Figure 1, Additional file 1: Figure S1). Their short stature was associated with severe osteopenia, mild growth hormone deficiency (levels -2.2 to -3 SDS), but appropriate bone age and normal calcium, phosphate, alkaline phosphatase serum levels (Figure 1). Vitamin D supplementation over 8 months did not improve osteopenia.

We identified the largest intragenic $R A B 3 G A P 1$ microdeletion published to date in the index patients through combined Sanger sequencing and array CGH (arr[hg19] $2 q 21.3(135.837 .294 \times 2,135.857 .789-135.872 .940 \times$ $0,135.896 .068 \times 2)$ and $\operatorname{arr}[$ hg19]4p16.3(68.185 $\times 2,72.477-$ $156.130 \times 1,165.852 \times 2)$ ) and further characterized the deletion breakpoints using multiple PCR amplicons (Figure 1, Additional file 2: Supplemental Data). The additional small 4p16.3-deletion, containing parts of the genes ZNF718 and ZNF595 is likely not relevant for the phenotype of the patients. The deletion is very small, encompassing only $84 \mathrm{~kb}$, and overlaps with deletions documented in the normal population in the database of genomic variants (DGV). All deletions listed in decipher affecting the respective chromosome are vastly larger. Moreover, both corresponding genes have not been associated with clinical phenotypes (search in: OMIM, PubMed, Uniprot, Genecards). However, we confirmed a homozygous 2q21.3-deletion of $50.4 \mathrm{~kb}$ encompassing exons 4-15 of RAB3GAP1 corresponding to about $45 \%$ of the coding gene sequence: $135,840,320-135,891,847$ (hg 19) in both patients, which is heterozygous in the parents as shown by qPCR. The extensive size of the patients' deletion, their phenotypes resemble previous descriptions of WARBM1 (Table 1), thereby firmly supporting the theory that all WARBM1 phenotypes are caused by a loss of RAB3GAP1 function and/or by nonsensemediated mRNA decay. Surprisingly, some WARBM1associated neuro-ophthalmological anomalies were absent in our patients, such as ptosis and nystagmus, delayed myelination, cerebral atrophy, and seizures [1,2,8-11]. Such mild phenotypic variability of WARBM1 is not well understood.

Osteopenia present in our patients has not been highlighted in WARBM so far. While osteopenia can result from vitamin $D$ deficiency, it may also be caused by RAB3GAP1 dysfunction itself as RAB3GAP1 arrests the activity of the osteoclastic bone resorption promoter RAB3D [12]. Uncontrolled activity of the latter is associated with bone structure defects in humans [12]. Osteopenia through RAB3GAP1 deficiency is supported by (i) the serum findings in our patients arguing against a severe rachitis secondary to vitamin D deficiency and (ii) the ineffectiveness of vitamin $\mathrm{D}$ supplementation with respect to osteopenia in the patients. 
In summary, we report that even the largest microdeletion of $45 \%$ of RAB3GAP1 provokes a rather typical WARBM1 phenotype. We thereby strongly support the theory that all truncating RAB3GAP1 mutations generate a loss-of-protein-function and/or nonsense-mediatedmRNA-decay and therefore result in a similar phenotype. Only hypomorphic RAB3GAP1 mutations induce the milder Martsolf syndrome phenotype [5,9,13]. Severe osteopenia needs to be considered as a feature of WARBM, and future insight into the role of RAB3D in WARBM may help to understand skeletal abnormalities and assist in establishing a therapeutic approach.

\section{Consent statement}

Written informed consent was obtained from the patients' legal guardian for publication of this case report and any accompanying images. A copy of the written consent is available for review by the Editor-in-Chief of this journal.

\section{Additional files}

Additional file 1: Figure S1. Cranial MRI of index patient IV.1 with WARBM 1 .

Additional file 2: Supplemental Data.

\section{Abbreviations}

RAB3GAP1: RAB3 GTPase-activating protein 1; RAB3GAP2: RAB3 GTPaseactivating protein 2; RAB18: RAS-associated protein RAB18; TBC1D20: TBC1 domain protein, member 20; WARBM: Warburg micro syndrome;

SDS: Standard deviation score.

\section{Competing interests}

The authors declare that they have no competing interests.

\section{Authors' contributions}

$\mathrm{CH}, \mathrm{AMK}$, and SPM recruited subjects, gathered patient history as well as clinical information and contributed clinical samples. BS analyzed radiological images. EK and DH performed array CGH and further genetic analysis. $A B$ and $B H$ analyzed the breakpoint boundaries of the patient's deletion. SPM and AMK wrote the manuscript, which was read, corrected and approved by all coauthors.

\section{Authors' information}

SPM is a Resident in Pediatrics interested in Pediatric Neurology. $\mathrm{CH}$ is head of the Pediatric Neurology Department of the Charité, and AMK is a Pediatric Neurologists and Clinical Scientist working on developmental diseases. $A B, B H, E K$, and $D H$ are Geneticists; DH heads the Genetic Outpatient Clinic. BS heads the Department of Pediatric Radiology.

\section{Acknowledgements}

The authors thank Theodor Michael, Jessica Fassbender, Björn Picker, and Christine Zeschnigk for discussions and technical assistance. Our research was supported by the German Research Foundation (DFG; SFB665), the Sonnenfeld Stiftung, the Deutsche Gesellschaft für Muskelerkrankungen (DGM), and the Berlin Institute of Health (BIH).

\section{Author details}

${ }^{1}$ Department of Pediatric Neurology, Charité - Universitätsmedizin Berlin, Campus Virchow-Klinikum, Augustenburger Platz 1, 13353 Berlin, Germany. ${ }^{2}$ SPZ Pediatric Neurology, Charité - Universitätsmedizin Berlin, Campus Virchow-Klinikum, Augustenburger Platz 1, 13353 Berlin, Germany. ${ }^{3}$ Institute of Neurobiology and Cell Biology, Charité - Universitätsmedizin Berlin, Campus
Mitte, Charitéplatz 1, 10115 Berlin, Germany. ${ }^{4}$ Institute of Human Genetics, University Medical Center Freiburg, Breisacher Str. 33, 79106 Freiburg, Germany. ${ }^{5}$ Department of Pediatric Radiology, Charité - Universitätsmedizin Berlin, Campus Virchow-Klinikum, Augustenburger Platz 1, 13353 Berlin, Germany. ${ }^{6}$ Institute of Medical and Human Genetics, Charité - Universitätsmedizin Berlin, Campus Virchow-Klinikum, Augustenburger Platz 1, 13353 Berlin, Germany. ${ }^{7}$ Current address: Institute of Human Genetics, University of Würzburg, Biozentrum Am Hubland, 97074 Würzburg, Germany.

Received: 8 May 2014 Accepted: 7 July 2014

Published online: 21 October 2014

\section{References}

1. Aligianis IA, Johnson CA, Gissen P, Chen D, Hampshire D, Hoffmann K, Maina EN, Morgan NV, Tee L, Morton J, Ainsworth JR, Horn D, Rosser E, Cole TRP, Stolte-Dijkstra I, Fieggen K, Clayton-Smith J, Mégarbané A, Shield JP, Newbury-Ecob R, Dobyns WB, Graham JM, Kjaer KW, Warburg M, Bond J, Trembath RC, Harris LW, Takai Y, Mundlos S, Tannahill D, Woods CG, Maher ER: Mutations of the catalytic subunit of RAB3GAP cause Warburg Micro syndrome. Nat Genet 2005, 37:221-224.

2. Morris-Rosendahl DJ, Segel R, Born AP, Conrad C, Loeys B, Brooks SS, Müller L, Zeschnigk C, Botti C, Rabinowitz R, Uyanik G, Crocq M-A, Kraus U, Degen I, Faes F: New RAB3GAP1 mutations in patients with Warburg Micro Syndrome from different ethnic backgrounds and a possible founder effect in the Danish. Eur J Hum Genet EJHG 2010, 18:1100-1106.

3. Warburg M, Sjö O, Fledelius HC, Pedersen SA: Autosomal recessive microcephaly, microcornea, congenital cataract, mental retardation, optic atrophy, and hypogenitalism. Micro syndrome. Am J Dis Child 1960 1993, 147:1309-1312.

4. Bem D, Yoshimura S-I, Nunes-Bastos R, Bond FC, Bond FF, Kurian MA, Rahman F, Handley MTW, Hadzhiev Y, Masood I, Straatman-Iwanowska AA, Cullinane AR, McNeill A, Pasha SS, Kirby GA, Foster K, Ahmed Z, Morton JE, Williams D, Graham JM, Dobyns WB, Burglen L, Ainsworth JR, Gissen P, Müller F, Maher ER, Barr FA, Aligianis IA: Loss-of-function mutations in RAB18 cause Warburg micro syndrome. Am J Hum Genet 2011, 88:499-507.

5. Borck G, Wunram H, Steiert A, Volk AE, Körber F, Roters S, Herkenrath $P$, Wollnik B, Morris-Rosendahl DJ, Kubisch C: A homozygous RAB3GAP2 mutation causes Warburg Micro syndrome. Hum Genet 2011, 129:45-50.

6. Corbeel L, Freson K: Rab proteins and Rab-associated proteins: major actors in the mechanism of protein-trafficking disorders. Eur J Pediatr 2008, 167:723-729.

7. Liegel RP, Handley MT, Ronchetti A, Brown S, Langemeyer L, Linford A, Chang B, Morris-Rosendahl DJ, Carpanini S, Posmyk R, Harthill V, Sheridan E, Abdel-Salam GMH, Terhal PA, Faravelli F, Accorsi P, Giordano L, Pinelli L, Hartmann B, Ebert AD, Barr FA, Aligianis IA, Sidjanin DJ: Loss-of-function mutations in TBC1D20 cause cataracts and male infertility in blind sterile mice and Warburg micro syndrome in humans. Am J Hum Genet 2013, 93:1001-1014

8. Graham JM Jr, Hennekam R, Dobyns WB, Roeder E, Busch D: MICRO syndrome: an entity distinct from COFS syndrome. Am J Med Genet $A$ 2004, 128A:235-245.

9. Handley MT, Morris-Rosendahl DJ, Brown S, Macdonald F, Hardy C, Bem D, Carpanini SM, Borck G, Martorell L, Izzi C, Faravelli F, Accorsi P, Pinelli L, Basel-Vanagaite L, Peretz G, Abdel-Salam GMH, Zaki MS, Jansen A, Mowat D, Glass I, Stewart H, Mancini G, Lederer D, Roscioli T, Giuliano F, Plomp AS, Rolfs A, Graham JM, Seemanova E, Poo P, García-Cazorla A, Edery P, Jackson IJ, Maher ER, Aligianis IA: Mutation spectrum in RAB3GAP1, RAB3GAP2, and RAB18 and genotype-phenotype correlations in warburg micro syndrome and Martsolf syndrome. Hum Mutat 2013, 34:686-696.

10. Mégarbané A, Choueiri R, Bleik J, Mezzina M, Caillaud C: Microcephaly, microphthalmia, congenital cataract, optic atrophy, short stature, hypotonia, severe psychomotor retardation, and cerebral malformations: a second family with micro syndrome or a new syndrome? I Med Genet 1999, 36:637-640.

11. Abdel-Salam GMH, Hassan NA, Kayed HF, Aligianis IA: Phenotypic variability in Micro syndrome: report of new cases. Genet Couns Geneva Switz 2007, 18:423-435.

12. Pavlos NJ, Xu J, Riedel D, Yeoh JSG, Teitelbaum SL, Papadimitriou JM, Jahn $\mathrm{R}$, Ross FP, Zheng MH: Rab3D regulates a novel vesicular trafficking pathway that is required for osteoclastic bone resorption. Mol Cell Biol 2005, 25:5253-5269. 
13. Aligianis IA, Morgan NV, Mione M, Johnson CA, Rosser E, Hennekam RC, Adams G, Trembath RC, Pilz DT, Stoodley N, Moore AT, Wilson S, Maher ER: Mutation in Rab3 GTPase-activating protein (RAB3GAP) noncatalytic subunit in a kindred with Martsolf syndrome. Am J Hum Genet 2006, 78:702-707.

14. Robinson PN, Köhler S, Bauer S, Seelow D, Horn D, Mundlos S: The Human Phenotype Ontology: a tool for annotating and analyzing human hereditary disease. Am J Hum Genet 2008, 83:610-615.

doi:10.1186/s13023-014-0113-9

Cite this article as: Picker-Minh et al: Large homozygous RAB3GAP1 gene microdeletion causes Warburg Micro Syndrome 1. Orphanet Journal of Rare Diseases 2014 9:113.

\section{Submit your next manuscript to BioMed Central and take full advantage of:}

- Convenient online submission

- Thorough peer review

- No space constraints or color figure charges

- Immediate publication on acceptance

- Inclusion in PubMed, CAS, Scopus and Google Scholar

- Research which is freely available for redistribution 